Review

\title{
Fundamental Elucidation of HLA in Type 1 Diabetes of Arab Populations
}

\author{
Running title: Arab HLA and type 1 diabetes
}

Mohamed Mirza Jahromi

Population genetics, Clinical Research Department, Clinical Division, Dasman Diabetes Institute, P.O Box 1180, Dasman 15462, Kuwait; mjahromi@yahoo.com

\begin{abstract}
Aims/Hypothesis): Type 1 diabetes is an immune-mediated disease with destruction of the pancreatic $\beta$-cells, a process that is conditioned by multiple genes and other factors. HLA counts as the major susceptibility gene. Significant variations in HLA genetic susceptibility to type 1 diabetes between Caucasians, African and Asian and other ethnic groups may have led to the variation in incidence of type 1 diabetes globally. Type 1 diabetes is characterized upon HLA identification. In this chapter we discuss global variations in genetic susceptibility of HLA with regard to type 1 diabetes globally with a particular attention to Arab population. Methods): Haplotype configuration of HLA class I A, B, C and Class II -DR/DQ/DP were studied in Caucasians, African and Asian and in Arab population to see if that is responsible for the exponential rise in the rate of type 1 diabetes. Results): Although Arabs have one of the highest global incidence and prevalence rates of type 1 diabetes, unfortunately, there is a dearth amount of information regarding HLA genetic susceptibility to type 1 diabetes in the Arab world. HLA haplotype configurations contribute to its risk value. However, out of an insufficient present study there are examples of misjudgment of HLA risk according to HLA alleles rather than haplotypes. Conclusion): To date HLA outlooks for the characterization of type 1 diabetes. There is an ethnicity difference in HLA characteristics which is responsible for variation in type 1 diabetes. Although Arab population have contributed heavily in the rise of burden of type 1 diabetes, however, there is significantly a dearth amount of studies on HLA in Arab population. Obviously, any future prediction, prevention or cure of the disease will be based on the HLA genetics. There is a dire need for a systematic screening of HLA for Arab population with type 1 diabetes, identification of Arab HLA haplotypes-risk values and identify those who are prone to get the disease.
\end{abstract}

Keywords: HLA; type 1 diabetes; ethnicity; screening; haplotype

\section{Abbreviations: HLA: Human Leukocyte Antigen}

\section{Introduction}

Type 1 diabetes is one of the most common endocrine and metabolic conditions in childhood. The number of children developing this form of diabetes is increasing exponentially. Usually, the incidence of type 1 diabetes is considered to account for 10-15\% of total diabetes [1]. Yearly 86,000 new cases of type 1 diabetes is added to the number of children below 15 years old. In 2015 it was estimated that the total of 542,000 children below 15 years old equivalent to 2.82 per 1000,000 children at the same age had type 1 diabetes [2]. The overall incidence of type 1 diabetes varied from 0.1/100,000 per year in China, Papua New Guinea and Venezuela to 57.6/100,000 per year in Finland with an approximately 600-fold gradient of among countries, Figure 1 . The incidence varies within 
several other countries including Italy where Sardinia is notably discordant with the incidence in Italy as a whole (51.0 vs 12.1 / 100,000 population) [3] . China is another country where there is a 12fold variation by region (0.13-1.61/100,000) [4]. In general, countries in Europe and North America have either a high or intermediate incidence. The incidence in North Africa is generally intermediate, similar to Southern Europe, and that in Asia is reported to be low in Japan, China and Korea, and also low in populations in South America with a high native Indian ancestry [2]. Interestingly, Saudi Arabia and Kuwait which are from high income Arab countries are between top ten countries with high type 1 diabetes incidence rates [2]. Remarkably, the rate of incidence of type 1 diabetes varies 12.5 fold in high income oil producing Arab countries in the Gulf region (31.4 Saudi Arabia vs 2.5 Oman/ 100,000 population), Figure 2.

\section{Human Leukocyte Antigen (HLA)}

HLA counts for almost $50 \%$ of type 1 diabetes genetic susceptibility [5]. HLA complex is located on chromosome 6 in the 6 p21.31 region containing the most polymorphic genes with more than 14,000 alleles [6]. Due to the high linkage disequilibrium, it is difficult to determine which gene or combinations of genes (haplotypes) in the HLA complex are directly responsible in the etiology of the disease. It is believed that HLA haplotype configuration lead to variation of rates of type 1 diabetes [7] The HLA genes mainly responsible for type 1 diabetes are class I (A, B and C) and class II (DR, DQ and DP) (Table 1). To date, out of 14,473 HLA alleles 14, 282 were reported for HLA Class I and Class II with a different mode of action which is responsible for the complex etiology of the disease[6]. Family studies have shown that in the Caucasoid population, several HLA class I alleles result in the predisposition of type 1 diabetes and may also be involved in type 2 diabetes [8]. The same susceptibility alleles have been reported in East Asian populations [7]. Different ethnicities may, however, have similar or different HLA class I susceptibilities associated with the manifestation of type 1 diabetes [9-13].

The role of HLA class II has been emphasized in the context of the antigen-presenting process in type 1 diabetes [14], but it remains to be elucidated how a certain HLA class II can contribute toward the molecular mechanisms of $\beta$-cell destruction in type 1 diabetes $[15,16]$. HLA class II DR, DQ and DP association with type 1 diabetes have been shown to vary amongst different populations and ethnicities as well [7,17-20]. In Caucasian populations up to $90 \%$ of patients with type 1 diabetes are carriers of DR3 or DR4 [21,22]. HLA-DR3/DR4 is reported in 30\% to $50 \%$ patients with type 1 diabetes which confers the highest diabetes risk with a synergistic mode of action [8] However, DR4/DR9 has been reported to be a highly susceptible haplotype in Japanese. The absence of DR3 haplotypes in the Japanese population may contribute to lower frequency of the disease in Japan [23]. On the other hand, in the Chinese population the DR3/DR9 genotype is highly susceptible [24]. In the Japanese population DR4 is a predisposing haplotype whereas DR8, DR9 and DR13 are general risk variants in Asian populations [25]. Furthermore, disease risk assessment for African Americans differs greatly from risk assessment in other characterized populations. Both DRB1*07:01 and DRB1*03:03 haplotypes are of high risk when they include DQA1*03:01-DQB1*02:01 [26,27].

HLA DP allelic and haplotype diversity contributes significantly to the risk for type 1 diabetes. In the Caucasian populations DP 301 (DPA1*0103-DPB1*0301) and DP 202 (DPA1*103, DPB1*0202) is associated with susceptibility and DP402 (DPA1*0103-DPB1*0402) and DP 101(DPA1*0103DPB1*0101) not. Additional evidence is presented for the susceptibility association of DP 202 (DPA1*0103-DPB1*0202) and for a contributory role of individual amino acids and DPA1 or a gene in linkage disequilibrium in DR3-DP101 positive haplotypes [28].In controversy, in a more recent study on the Japanese population, it showed that the DP202 allele is also concurrent with type 1 diabetes [29]. Whereas, in the Venezuelan population DP 202 was the only haplotype associated with type 1 diabetes $[17,30]$. Furthermore, haplotypes DPA2/DPB1 were susceptible to type 1 diabetes in American Indians [19]. These data and their comparison with HLA DR-DQ-DP haplotypes in more homogeneous ethnic groups support the existence of a weak association of type 1 diabetes with specific HLA DP alleles and indicate how the distribution of these DP alleles could differ depending 
on the ethnic groups studied [19]. Table 2 summarizes classification of HLA-DR in different populations and their diabetes risk level [7-15,17-25,28-40].

HLA alleles are not randomly transmitted from parent to their offspring, but as a block with a strong linkage disequilibrium between A, C, B, DR and DQ alleles, i.e. haplotypes. Remarkably, only a limited number of type 1 susceptibility haplotypes seem to exist. For instance, in Finland with the world's highest incidence of type 1 diabetes only 37 different HLA haplotypes were identified among diabetic children who had either a parent or sibling with type 1 diabetes, and another 18 haplotypes in children who did not have a first degree relative with type 1 diabetes [41].

There are only a few HLA studies in Arab countries that compare their contribution in the rise of the burden of the disease globally, Table 3 [2,42-48]. These studies have set the stepping stone to elucidate the type 1 diabetes genetic risk factors in the Arab population [42-48]. On the other hand, the advancement of technology and uniqueness of some of the Arab population in terms of consanguinity and uncharacterized type 1 diabetes can add valuable information in the understanding of type 1 diabetes pathogenesis. The gaining of novel knowledge for 'new' uncharacterized populations may enable us to discover new haplotypes and compare them with other African, Caucasoid and Asian populations; to understand both differences and similarities in the genetic predisposition of type 1 diabetes [2]. There is a dire need for systematic HLA haplotype studies in Arab populations. Recently, however, a meta-analysis was published in 2015 analyzing 23,333 articles; interestingly, only 30 of them were from Arab population. The studies in Arab populations have mainly discussed genetic susceptibility of type 1 diabetes related to HLA-DR or DQ alleles but not haplotype configurations [49]. The hallmark of HLA susceptibility, however, is considered from haplotype configuration $[5,7,41,50]$.

Furthermore, the presence of DR9 haplotype has been proposed to be a factor for the low rate type 1 diabetes in the Japanese population [7] In fact, variation in HLA-DR locus in HLA haplotypes in different populations obviously explain part of the world-wide differences in the frequency of incidence of type 1 diabetes, but it is not fully understood how this is actually happening, since only limited comparisons of HLA haplotypes in type 1 diabetes among populations are available $[19,23,40]$.

Indeed HLA is considered as the key for characterization of type 1 diabetes. Systematic screening of Arab type 1 diabetes patients with their first degree relatives for HLA-risk haplotypes will elucidate those who are prone to get type 1 diabetes. Any future advancement, predication and prevention of the disease will be based of the HLA characteristics of the disease. HLA characterization of Caucasian population with type 1 diabetes is almost well-known, however, still further studies are on-going $[5,51,52]$ which reflect the significant impact of this gene in the pathogenesis of the disease.

\section{Discussion}

The global distribution of childhood type 1 diabetes clearly indicates large area-to-area variations. Comparing to the neighboring countries to Arab countries in general and high-income Oil-producing Arab countries in particular have the highest prevalence of type 1 diabetes, Figure 2 . Rapid economic development coupled with ageing populations have resulted in a dramatic increase in the prevalence of type 1 diabetes. Over the past three decades, major social and economic changes have occurred in the majority of Arab countries especially in the Gulf region. These include progressive urbanization, decreased infant mortality and increasing life expectancy.

Different populations may have similar or diverse HLA susceptibilities associated with the manifestation of type 1 diabetes. This short study had many limitations because of the paucity of T1D in Arab countries studies in general and HLA as the most promising gene to solve the riddle of type 1 diabetes and speed the prevention of this terrible disease in particular. Careful multicenter Arab population-wide study with different culture and immunogenetics than America and Europe should help us to solve this endemic disease. A suitable screening regimen to characterize Arab type 1 diabetes, no doubt, will help to identify those who are prone to get the disease in the early stages of 
their life. Undoubtedly this would unravel puzzle of type 1 diabetes and reducing the disease related economic burden.

\section{Concluding Remarks}

The incidence of type 1 diabetes is increasing globally and has become epidemic in some countries. Environmental factors may explain part of such differences, however, we might have to revise the hypothesis of equatorial gradient as the rate of disease in high income oil producing Arab countries, being in an environment totally different than Finland and Sardinia or the United States of America, is growing continuously.

HLA counts for almost $50 \%$ of type 1 diabetes genetic susceptibility and is a key indicator for characterization of type 1 diabetes. Various HLA haplotypes were reported among different populations with variable rates of type 1 diabetes. Such variety of HLA haplotypes may explain the remarkable differences in type 1 incidence among populations. Undoubtedly, any future preventive management and therapy will encounter HLA configuration. HLA is not well studied in Arab populations. Although Arab population contribute heavily on the rise of type 1 diabetes burden only few studies have been produced from this region. There is a dire need for systematic multicenter Arab population study of HLA in type 1 diabetes patients to identify Arab HLA risk haplotypes for the disease. The latter will contribute significantly in characterization of Arab type 1 diabetes and its pathogenesis.

\section{Acknowledgement}

Author would like to acknowledge Professor Jaakko Tuomilehto, CSO, Dasman Diabetes Institute, Kuwait for his time and proof reading the current manuscript. As I would like to express my appreciation to Professor Flemming Pociot, CPH-DIRECT, Denmark for his time and sincere advice.

\section{Competing Interest:}

The author declare that they have no competing interests.

\section{References:}

1. Fsadni P, Fsadni C, Fava S, Montefort S (2012) Correlation of worldwide incidence of type 1 diabetes (DiaMond) with prevalence of asthma and atopic eczema (ISAAC). Clin Respir J 6: $18-25$.

2. Federation. ID (2013) Diabetes Atlas 6th edition.

3. Forouhi NG, Wareham NJ (2014) Epidemiology of diabetes. Medicine (Abingdon) 42: 698-702.

4. Tuomilehto J (2013) The emerging global epidemic of type 1 diabetes. Curr Diab Rep 13: 795-804.

5. Aly TA, Ide A, Jahromi MM, Barker JM, Fernando MS, et al. (2006) Extreme genetic risk for type 1A diabetes. Proc Natl Acad Sci U S A 103: 14074-14079.

6. Robinson J, Halliwell JA, Marsh SG (2014) IMGT/HLA and the Immuno Polymorphism Database. Methods Mol Biol 1184: 109-121.

7. Jahromi MM, Eisenbarth GS (2006) Genetic determinants of type 1 diabetes across populations. Ann N Y Acad Sci 1079: 289-299.

8. Noble JA, Erlich HA (2012) Genetics of type 1 diabetes. Cold Spring Harb Perspect Med 2: a007732.

9. Stankov K, Benc D, Draskovic D (2013) Genetic and epigenetic factors in etiology of diabetes mellitus type 1. Pediatrics 132: 1112-1122.

10. Noble JA, Valdes AM, Bugawan TL, Apple RJ, Thomson G, et al. (2002) The HLA class I A locus affects susceptibility to type 1 diabetes. Hum Immunol 63: 657-664.

11. Tait BD, Colman PG, Morahan G, Marchinovska L, Dore E, et al. (2003) HLA genes associated with autoimmunity and progression to disease in type 1 diabetes. Tissue Antigens 61: 146153. 
12. Valdes AM, Erlich HA, Noble JA (2005) Human leukocyte antigen class I B and C loci contribute to Type 1 Diabetes (T1D) susceptibility and age at T1D onset. Hum Immunol 66: 301-313.

13. Nejentsev S, Howson JM, Walker NM, Szeszko J, Field SF, et al. (2007) Localization of type 1 diabetes susceptibility to the MHC class I genes HLA-B and HLA-A. Nature 450: 887-892.

14. Eisenbarth GS PK, Buse JB (2003) Type 1 diabetes mellitus. 1485-1504 p.

15. Imagawa A, Hanafusa T (2006) [Fulminant type 1 diabetes]. Nihon Rinsho Suppl 3: 37-41.

16. Barrett JC, Clayton DG, Concannon P, Akolkar B, Cooper JD, et al. (2009) Genome-wide association study and meta-analysis find that over 40 loci affect risk of type 1 diabetes. Nat Genet 41: 703-707.

17. Liao Y, Cai B, Li Y, Chen J, Ying B, et al. (2014) Association of HLA-DP/DQ, STAT4 and IL-28B variants with $\mathrm{HBV}$ viral clearance in Tibetans and Uygurs in China. Liver Int.

18. Cucca F, Dudbridge F, Loddo M, Mulargia AP, Lampis R, et al. (2001) The HLA-DPB1-associated component of the IDDM1 and its relationship to the major loci HLA-DQB1, DQA1, and -DRB1. Diabetes 50: 1200-1205.

19. Cruz TD, Valdes AM, Santiago A, Frazer de Llado T, Raffel LJ, et al. (2004) DPB1 alleles are associated with type 1 diabetes susceptibility in multiple ethnic groups. Diabetes 53: 21582163.

20. Howson JM, Walker NM, Clayton D, Todd JA, Type 1 Diabetes Genetics C (2009) Confirmation of HLA class II independent type 1 diabetes associations in the major histocompatibility complex including HLA-B and HLA-A. Diabetes Obes Metab 11 Suppl 1: 31-45.

21. Sanjeevi CB, Landin-Olsson M, Kockum I, Dahlquist G, Lernmark A (1995) Effects of the second HLA-DQ haplotype on the association with childhood insulin-dependent diabetes mellitus. Tissue Antigens 45: 148-152.

22. Thorsby E, Gjertsen HA, Lundin KE, Ronningen KS (1991) Insulin dependent diabetes mellitus susceptibility or protection may be determined by certain HLA-DQ molecules. Baillieres Clin Endocrinol Metab 5: 361-373.

23. Ikegami H, Noso S, Babaya N, Hiromine Y, Kawabata Y (2008) Genetic Basis of Type 1 Diabetes: Similarities and Differences between East and West. Rev Diabet Stud 5: 64-72.

24. Zhang XM, Wang HY, Luo YY, Ji LN (2009) HLA-DQ, DR allele polymorphism of type 1 diabetes in the Chinese population: a meta-analysis. Chin Med J (Engl) 122: 980-986.

25. Katahira M, Ishiguro T, Segawa S, Kuzuya-Nagao K, Hara I, et al. (2008) Reevaluation of human leukocyte antigen DR-DQ haplotype and genotype in type 1 diabetes in the Japanese population. Horm Res 69: 284-289.

26. Noble JA, Johnson J, Lane JA, Valdes AM (2011) Race-specific type 1 diabetes risk of HLA-DR7 haplotypes. Tissue Antigens 78: 348-351.

27. Noble JA, Johnson J, Lane JA, Valdes AM (2013) HLA class II genotyping of African American type 1 diabetic patients reveals associations unique to African haplotypes. Diabetes 62: 3292-3299.

28. Varney MD, Valdes AM, Carlson JA, Noble JA, Tait BD, et al. (2010) HLA DPA1, DPB1 alleles and haplotypes contribute to the risk associated with type 1 diabetes: analysis of the type 1 diabetes genetics consortium families. Diabetes 59: 2055-2062.

29. Jassam N, Amin N, Holland P, Semple RK, Halsall DJ, et al. (2014) Analytical and clinical challenges in a patient with concurrent type 1 diabetes, subcutaneous insulin resistance and insulin autoimmune syndrome. Endocrinol Diabetes Metab Case Rep 2014: 130086.

30. Solberg OD, Mack SJ, Lancaster AK, Single RM, Tsai Y, et al. (2008) Balancing selection and heterogeneity across the classical human leukocyte antigen loci: a meta-analytic review of 497 population studies. Hum Immunol 69: 443-464.

31. Ikegami H, Kawaguchi Y, Yamato E, Kuwata S, Tokunaga K, et al. (1992) Analysis by the polymerase chain reaction of histocompatibility leucocyte antigen-DR9-linked susceptibility to insulin-dependent diabetes mellitus. J Clin Endocrinol Metab 75: 1381-1385.

32. Awata T, Kuzuya T, Matsuda A, Iwamoto Y, Kanazawa Y (1992) Genetic analysis of HLA class II alleles and susceptibility to type 1 (insulin-dependent) diabetes mellitus in Japanese subjects. Diabetologia 35: 419-424. 
33. Kawabata Y, Ikegami H, Kawaguchi Y, Fujisawa T, Shintani M, et al. (2002) Asian-specific HLA haplotypes reveal heterogeneity of the contribution of HLA-DR and -DQ haplotypes to susceptibility to type 1 diabetes. Diabetes 51: 545-551.

34. Murao S, Makino H, Kaino Y, Konoue E, Ohashi J, et al. (2004) Differences in the contribution of HLA-DR and -DQ haplotypes to susceptibility to adult- and childhood-onset type 1 diabetes in Japanese patients. Diabetes 53: 2684-2690.

35. Ohtsu S, Takubo N, Kazahari M, Nomoto K, Yokota F, et al. (2005) Slowly progressing form of type 1 diabetes mellitus in children: genetic analysis compared with other forms of diabetes mellitus in Japanese children. Pediatr Diabetes 6: 221-229.

36. Yasunaga S, Kimura A, Hamaguchi K, Ronningen KS, Sasazuki T (1996) Different contribution of HLA-DR and -DQ genes in susceptibility and resistance to insulin-dependent diabetes mellitus (IDDM). Tissue Antigens 47: 37-48.

37. Thomson G, Valdes AM, Noble JA, Kockum I, Grote MN, et al. (2007) Relative predispositional effects of HLA class II DRB1-DQB1 haplotypes and genotypes on type 1 diabetes: a metaanalysis. Tissue Antigens 70: 110-127.

38. Kasahara M, Kiuchi T, Uryuhara K, Uemoto S, Fujimoto Y, et al. (2002) Role of HLA compatibility in pediatric living-related liver transplantation. Transplantation 74: 11751180.

39. Maruyama T, Shimada A, Kasuga A, Kasatani T, Ozawa Y, et al. (1994) Analysis of MHC class II antigens in Japanese IDDM by a novel HLA-typing method, hybridization protection assay. Diabetes Res Clin Pract 23: 77-84.

40. Lipner EM, Tomer Y, Noble JA, Monti MC, Lonsdale JT, et al. (2013) HLA class I and II alleles are associated with microvascular complications of type 1 diabetes. Hum Immunol 74: 538544.

41. Tuomilehto-Wolf E, Tuomilehto J (1993) Is the high incidence of diabetes in young children diagnosed under the age of 4 years determined by genetic factors in Finland? The DIME Study Group. Diabete Metab 19: 167-172.

42. Fekih-Mrissa N, Klai S, Zaouali J, Gritli N, Mrissa R (2013) Association of HLA-DR/DQ polymorphism with myasthenia gravis in Tunisian patients. Clin Neurol Neurosurg 115: 32-36.

43. Mosaad YM, Auf FA, Metwally SS, Elsharkawy AA, El-Hawary AK, et al. (2012) HLA-DQB1* alleles and genetic susceptibility to type 1 diabetes mellitus. World J Diabetes 3: 149-155.

44. Aribi M, Moulessehoul S, Benabadji AB, Kendoucitani M (2004) HLA DR phenotypic frequencies and genetic risk of Type 1 diabetes in west region of Algeria, Tlemcen. BMC Genet 5: 24 .

45. Al-Jenaidi FA, Wakim-Ghorayeb SF, Al-Abbasi A, Arekat MR, Irani-Hakime N, et al. (2005) Contribution of selective HLA-DRB1/DQB1 alleles and haplotypes to the genetic susceptibility of type 1 diabetes among Lebanese and Bahraini Arabs. J Clin Endocrinol Metab 90: 5104-5109.

46. Al-Hussein KA, Rama NR, Ahmad M, Rozemuller E, Tilanus MG (2003) HLA-DPB1*0401 is associated with dominant protection against type 1 diabetes in the general Saudi population and in subjects with a high-risk DR/DQ haplotype. Eur J Immunogenet 30: 115119.

47. Behbehani K, Richens ER, Abdella N, Jayyab AK, Shaltout A, et al. (1987) HLA associations in an Arab type 1 diabetic population. Dis Markers 5: 165-169.

48. Haider MZ, Shaltout A, Alsaeid K, Qabazard M, Dorman J (1999) Prevalence of human leukocyte antigen DQA1 and DQB1 alleles in Kuwaiti Arab children with type 1 diabetes mellitus. Clin Genet 56: 450-456.

49. Hamzeh AR, Nair P, Al-Khaja N, Al Ali MT (2015) Association of HLA-DQA1 and -DQB1 alleles with type I diabetes in Arabs: a meta-analyses. Tissue Antigens 86: 21-27.

50. Jahromi MM, Eisenbarth GS (2007) Cellular and molecular pathogenesis of type 1A diabetes. Cell Mol Life Sci 64: 865-872. 
51. Aly TA, Baschal EE, Jahromi MM, Fernando MS, Babu SR, et al. (2008) Analysis of single nucleotide polymorphisms identifies major type 1A diabetes locus telomeric of the major histocompatibility complex. Diabetes 57: 770-776.

52. Aly TA, Eller E, Ide A, Gowan K, Babu SR, et al. (2006) Multi-SNP analysis of MHC region: remarkable conservation of HLA-A1-B8-DR3 haplotype. Diabetes 55: 1265-1269.

\section{Legends:}

\section{Table 1}

Type 1 diabetes associated number of alleles for each of the classical HLA loci are shown http://www.ebi.ac.uk/imgt/hla/stats.html.

\section{Table 2}

Classification of HLA-DR alleles and their risk level

\section{Table 3}

Some studies have clearly discussed HLA haplotype rather than allelic variations. Either whole studies or parts which were based on allelic variations were not included in this table.

\section{Figure 1}

Global reported rates of type 1 diabetes incidents/100,000 population in different countries.

\section{Figure 2}

Rates of type 1 diabetes in reported Arab countries

Table 1. Polymorphism at the classical HLA loci

\begin{tabular}{|c|c|}
\hline Locus & Number of alleles \\
\hline \multicolumn{2}{|c|}{ Class I $(n=10,591)$} \\
\hline$A$ & 3,399 \\
\hline$B$ & 4,242 \\
\hline$C$ & 2,950 \\
\hline \multicolumn{2}{|c|}{ Class II $(n=3,691)$} \\
\hline \multicolumn{2}{|l|}{$\overline{D R}$} \\
\hline$A$ & 7 \\
\hline$B$ & 2,018 \\
\hline \multicolumn{2}{|l|}{$D Q$} \\
\hline $\mathrm{A}$ & 69 \\
\hline $\mathrm{B}$ & 911 \\
\hline \multicolumn{2}{|l|}{$D P$} \\
\hline$A$ & 43 \\
\hline$B$ & 650 \\
\hline Total Number & 14,282 \\
\hline
\end{tabular}


Table 2: Classification of HLA-DR/DQ haplotypes and their risk level

\begin{tabular}{|c|c|c|c|c|c|}
\hline \multicolumn{4}{|c|}{$\begin{array}{l}\text { HLA- } \\
A 1 D Q B 1 D R B 1\end{array}$} & \multirow{2}{*}{$\begin{array}{c}\text { Susceptibility } \\
\text { Neutral }\end{array}$} & \multirow{2}{*}{$\begin{array}{c}\text { Population } \\
\text { Almost all }\end{array}$} \\
\hline DR2 & 0102 & 0602 & 1501 & & \\
\hline DR2 & 0102 & 0502 & 1601 & Moderate Risk & Caucasians \\
\hline DR2 & 0103 & 0601 & 1502 & Neutral & Caucasians \\
\hline DR3 & 0501 & 0201 & 0301 & High Risk & Caucasians, Koreans \\
\hline DR4 & 0301 & 0302 & 0401 & High Risk & Caucasians \\
\hline DR4 & 0301 & 0302 & 0402 & Moderate Risk & Caucasians \\
\hline DR4 & 0301 & 0302 & 0403 & Neutral & Caucasians \\
\hline DR4 & 0301 & 0302 & 0404 & Moderate Risk & Caucasians \\
\hline DR4 & 0301 & 0302 & 0405 & High Risk & Caucasians \\
\hline DR4 & 0301 & 0301 & 0401 & Neutral & Caucasians \\
\hline DR4 & 0301 & 0303 & 0401 & Neutral & Caucasians \\
\hline DR4 & 0405 & 0303 & 0401 & High Risk & Japanese, Koreans \\
\hline DR7 & 0201 & 0303 & 0701 & Neutral & Caucasians \\
\hline DR6 & 0101 & 0503 & 0401 & Neutral & Caucasians \\
\hline DR8 & 0802 & 0301 & 0302 & High Risk & Japanese \\
\hline DR9 & 0901 & 0300 & 0303 & High Risk & Japanese, Koreans \\
\hline DR13 & 1302 & 0102 & 0604 & High Risk & Japanese \\
\hline
\end{tabular}


Table 3: Classification of HLA-DR alleles and their risk level in Arab Populations

\begin{tabular}{|c|c|c|c|c|c|}
\hline \multicolumn{4}{|c|}{\begin{tabular}{|r} 
HLA \\
DRD QA1 \\
DQB1DRB1
\end{tabular}} & \multirow{2}{*}{\begin{tabular}{|l|} 
Susceptibility \\
High Risk
\end{tabular}} & \multirow{2}{*}{\begin{tabular}{|l|} 
Populations \\
$\begin{array}{l}\text { Bahraini, Kuwaiti, } \\
\text { Egyptian, Tunisian }\end{array}$ \\
\end{tabular}} \\
\hline DR3 & 0501 & 0201 & 0301 & & \\
\hline DR4 & 0301 & 0302 & 0405 & High Risk & Saudi Arabia, Algerian \\
\hline $\mathrm{DR} 2$ & 0102 & 0602 & 1501 & Neutral & Saudi Arabia, Algerian \\
\hline
\end{tabular}

Figure 1:

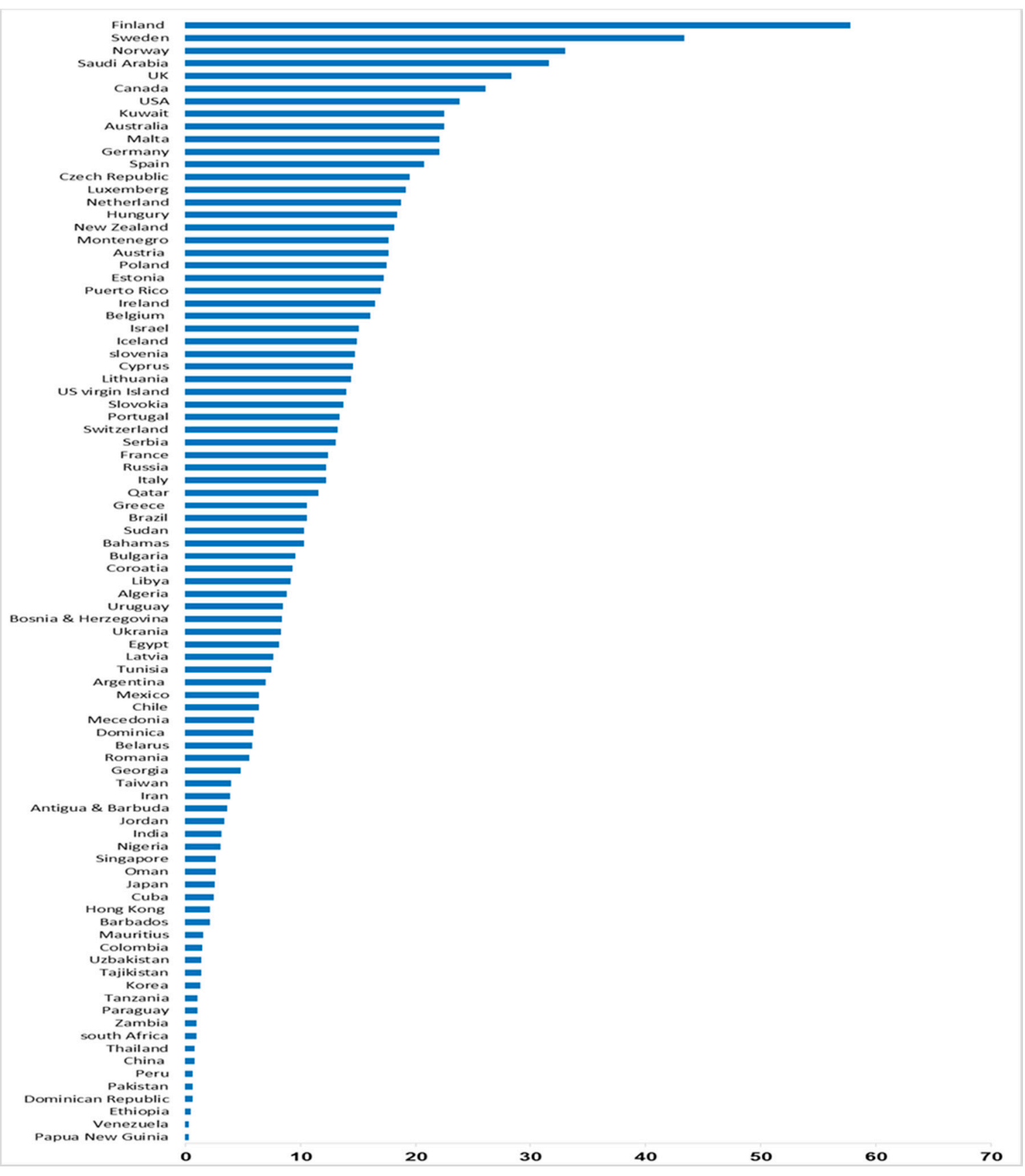


Figure 2:

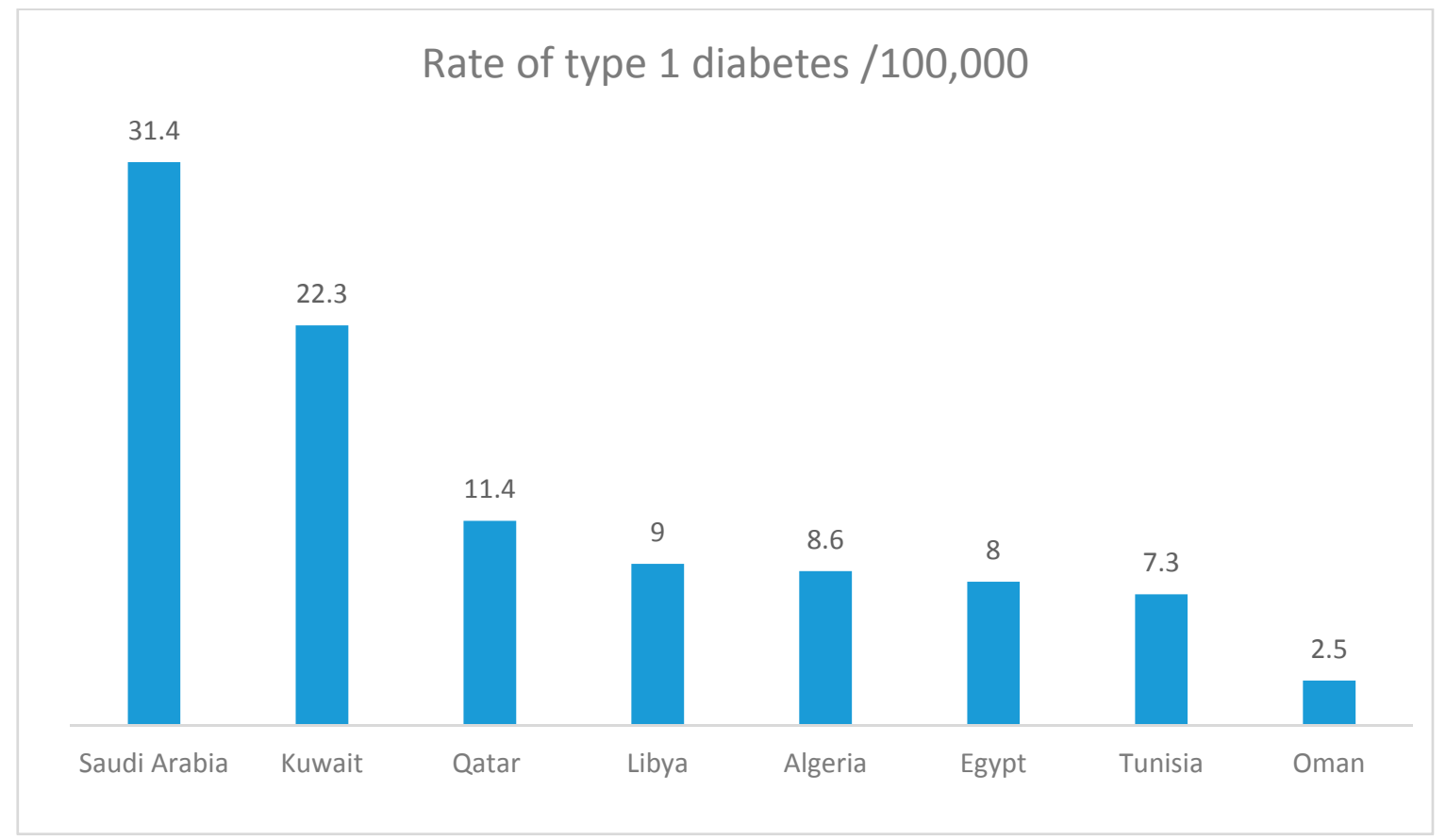

(C) 2016 by the author; licensee Preprints, Basel, Switzerland. This article is an open access article distributed under the terms and conditions of the Creative Commons by Attribution (CC-BY) license (http://creativecommons.org/licenses/by/4.0/). 